\title{
Health and safety in the workplace: prevention of hazards to reproductive health
}

\author{
C. Ferradans-Caramés ${ }^{1} \&$ F. González-Bugatto ${ }^{2}$ \\ ${ }^{1}$ Department of Labour Law, Cádiz University, Spain \\ ${ }^{2}$ Department of Obstetrics and Gynaecology, \\ "Puerta del Mar" Teaching Hospital, Cádiz, Spain
}

\begin{abstract}
Occupational exposure figures are inexact, and environmental levels are even more difficult to document. Exposure usually involves chemical mixtures, and individuals may not be aware of all the chemicals with which they come into contact. Thus, the effect of individual chemicals is difficult to assess, and causeand-effect relationships are nearly impossible to establish. The action plan, which should be drawn up by every employer, should specifically take into account when assessing the hazards involved in carrying out a particular job in a specific working environment, the factors which can have a bearing on the ability of the individual to have children, making a distinction between hazards which can affect women, and those which can affect men. Objective risk assessment should be made more specific, taking into consideration both the characteristics of the job and the individual by whom the said job is done.

Keywords: reproductive health, workplace, chemical hazards, labour risks prevention.
\end{abstract}

\section{The right to reproduction and occupational health}

The objective of our study is to analyse, from both a physiological and a legal perspective, the problems which arise at work which may be harmful to reproduction due to the characteristics of a working environment, the facilities, the chemical, physical or biological substances present, etc. The treatment of this question has to be distinct depending upon whether the potentially affected subject is female or male, given that the effects of these possibly detrimental factors could be different according to the gender variant [1]. 
Once the objective of this paper has been set out, we are going to endeavour to demarcate, from a constitutional perspective, the extent of the right to have children, and on what precepts that right to be protected is based.

To this end, it is essential to mention several Articles of the Spanish Constitution of 1978 (hereinafter SC). Thus in Article 15, the right to life and physical and moral well-being is declared as one of the most important and fundamental of constitutional rights. In Article 39 it is established that the authorities ought to guarantee social, economic and legal protection for the family, and in 39.3, specifically mothers. It is clear that in this Magna Carta, in a similar manner to those of our fellow European nations, the right to have children is not expressly recognised. Nevertheless, it is necessary to clarify that in all events the right to have children is one of the primordial manifestations of the right to physical well-being, for both men and women, just like their right to freedom, as the decision whether to have children or not is an exercise of the free will of the individual [2].

The right to have children is a right of autonomous choice for the individual, which brings about the birth of a series of rights and obligations and a necessity to avoid the obstacles which might arise in a working environment. In particular we refer to the protection which should be implemented as decreed by Article 40.2 of the SC, which establishes that the authorities will take care of safety and hygiene at work and Article 43, which recognises the right to health and safety.

This affirmation arises from the hypothesis that the right to have children forms part of health of an individual. Article 43 decrees the right to well being in a generic manner without defining what that consists of, thus permitting a flexible interpretation conditioned by the evolution of social and cultural factors in a given moment. To this end, the reason behind the prescription of the World Health Organisation (WHO) is obvious, as it considers that health is not only the absence of illness, but also "physical, psychological and social well-being" which, representing an ambitious goal, could be the outcome of an appropriate adaptation between the environment and the person.

Occupational health is defined more precisely in the in-session document of the first joint ILO (International Labour Organization)/WHO committee as "the requirements for establishing and maintaining a safe and healthy working environment which will facilitate optimal physical and mental health in relation to work and the adaptation of work to the capabilities of workers in the light of their state of physical and mental health." As such, occupational health is not only sustaining the absence of immediate risks for the worker, but also to progressively improve the wellbeing of said worker [3].

From the above, the framework of occupational health should be understood to encompass the protection of the reproductive facet of all workers, be they male or female, leading to the development of preventative measures, both individual and collective, in the face of multiple hazards which may confront the worker in a work environment [4]. However, this objective must also take into account the diversity in the prevention and protection required, depending upon the gender of the potentially affected subject, as the incidence of the different 
risks present can vary due to biological differences (hormonal, genetic, anatomical...).

\section{Chemical exposure and reproductive toxicity}

\subsection{Introduction}

The endocrine function of the gonads is primarily concerned with perpetuation of the species. The survival of any species depends on the integrity of its reproductive system. Genes located in the chromosomes of the germ cells ensure the maintenance of structure and function in the organism in its own lifetime and from generation to generation.

The twentieth century has undergone an industrial renaissance; through scientific and technical advances, there has been a significant extension in life expectancy and generally an enhanced quality of life. Concomitant to this industrial renaissance, an estimated 50,000 to 60,000 chemicals have come into common use. Approximately 600 or more new chemicals enter commerce each year [5].

The impact of new chemicals on the reproductive system was tragically accentuated by the thalidomide disaster in the 1960s [6]. This episode led to increased awareness on a worldwide basis and brought forth laws and guidelines pertaining to reproductive system safety and testing protocols.

The potential hazards posed to human reproduction by chemicals, and human risks from chemical exposure are difficult to assess because of the complexity of the reproductive process, the unreliability of laboratory tests, and the quality of human data.

The effects of environmental agents on sexual differentiation and the development of reproductive capacity are largely unknown. Of the chemicals that have been studied, it is worth noting that they possess a wide diversity in molecular structure and that they may affect specific cell populations within the reproductive system.

\subsection{Chemicals}

- Workers in waste incinerators are exposed to 1,2-dibromo-3-chloropropane $(D B C P)$ and suffer oligo-spermia, azoospermia, and germinal cell aplasia [7].

- Factory workers in battery plants in Bulgaria, lead mine workers in the U.S. state of Missouri, and workers in Sweden who handle organic solvents (toluene, benzene, and xylene) suffer from low sperm counts, abnormal sperm, and varying degrees of infertility.

- Diethylstilbestrol (DES), lead, chlordecone, methyl mercury, and many cancer chemotherapeutic agents have been shown to be toxic to the male and female reproductive systems and possibly capable of inflicting genetic damage to germ cells.

- Environmental estrogen mimics (e.g., DDT).

- Not only are there compounds in the environment that possess estrogenic properties, but there are also environmental antiandrogens (e.g., vinclozolin). 


\subsection{Biotransformation of exogenous chemicals}

When chemicals reach blood circulation they can be distributed by any tissue or organ of human economy. Often these chemicals suffer biotransformation reactions in metabolic organs, such as the liver or kidneys, becoming in some cases more potent toxics than the original substances. Some cases which affect the functioning of the testes are:

- $N$-hexane, yields 2,5-hexanedione (2,5-HD), an environmental toxicant, and this metabolite, that can be detected in urine from workers in the shoe industry, causes peripheral polyneuropathy and testicular atrophy [8].

- In workers of semiconductor manufacturing plants who are exposed to Ethylene glycol ethers, along with its metabolites, such as 2-methoxy-ethanol (2-ME) and 2-ethoxy-ethanol (2-EE) was found a increased risk of spontaneous abortion [9].

- Several heavy metals are known to adversely affect testicular function; Cadmium causes testicular toxicity.

- Esters of o-phthalic acid (phthalate esters or PAEs) are used extensively in medical devices and other consumer products as plasticizers. Because the PAEs are not convalently bound to the plastic, they can leach into the environment.

- Ethanol also causes delayed testicular development and may affect the Sertoli cell and/or the Leydig cell. Trifluoroethanol and trifluoroacetaldehyde produce specific damage to pachytene and dividing spermatocytes and round spermatids in rats.

- Antibiotics: Metabolites of cephalosporin reportedly cause testicular toxicity in rats. Testicular degeneration from analogs of cephalosporin is most likely to occur with cefbuperazone, cefamandole, and cefoperazone. Cyclosporine can also inhibit testosterone biosynthesis in the rat testes.

Less is known about how chemicals or drugs interfere with ovarian metabolism because of its more difficult and complex hormonal relationships.

Nevertheless, several chemotherapeutic agents can inhibit ovarian function: prednisone, vincristine, vinblastine, 6-mercaptopurine, nitrogen mustard, cyclophosphamide, chlorambucil, busulfan, methotrexate, cytosine arabinoside, L-asparginase, 5-fluorouracil and adriamycin [10].

\subsection{Targets for chemical toxicity: gonads}

The gonads are also targets for a host of drugs and chemicals [Table 1]. The majority of these agents are representatives of major chemical classes of cancer chemotherapeutic agents, particularly the alkylating agents. A number of endocrine agents are of value in the treatment of certain cancers. Antiestrogens (e.g., tamoxifen), aromatase inhibitors (e.g., aminoglutethimide), GnRH agonists and antagonists, and antiandrogens (e.g., flutamide) can interfere with the endocrine system. 
Table 1: $\quad$ Drugs that are gonadotoxic in humans.

\begin{tabular}{|l|l|}
\hline \multicolumn{1}{|c|}{ MALES } & \multicolumn{1}{c|}{ FEMALES } \\
\hline Busulfan & Busulfan \\
\hline Chlorambucil & Chlorambucil \\
\hline Cyclophosphamide & Cyclophosphamide \\
\hline Nitrogen mustard & Nitrogen mustard \\
\hline Doxorubicin & \\
\hline Corticosteroids & \\
\hline Cytosine-arabinoside & \\
\hline Methotrexate & \\
\hline Procarbazine & \\
\hline Vincristine & \\
\hline Vinblastine & Vinblastine \\
\hline
\end{tabular}

Procarbazine, an antineoplastic drug, causes severe damage to the acrosomal plasma membrane and the nucleus of the sperm head in hamsters. Alkylating agents (ultraviolet and $x$-rays) can damage DNA molecules and are effective against rapidly dividing cells. Not surprisingly, the division of germ cells is also affected, leading to arrest of spermatogenesis.

\subsection{Human risk factors affecting fertility}

Most humans are exposed to a vast number of chemicals that may be hazardous to their reproductive capacity. Many chemicals have been identified as reproductive hazards in laboratory studies [11]. Although the extrapolation of data from laboratory animals to humans is inexact, a number of these chemicals have also been shown to exert detrimental effects on human reproductive performance. The list includes drugs, especially steroid hormones and chemotherapeutic agents; metals and trace elements; pesticides; food additives and contaminants; industrial chemicals; and consumer products.

\subsubsection{Male fertility}

It has also been suggested that the human male is more vulnerable to environmental and occupational toxins than other mammals. It is noteworthy that chronic illness may have a profound affect on gonadal function [12]. Several systemic illnesses can reduce spermatogenesis, including thyrotoxicosis, hypothyroidism, renal failure, mumps, and Crohn's disease. A large number of nonhormonal diseases can likewise decrease serum testosterone as well as gonadotrophins. Aging, nutritional deficiencies, and obesity can affect fertility. Thus, a host of both endocrine and nonendocrine diseases can affect male fertility.

\subsubsection{Female fertility}

Many factors can affect the normal function of the female reproductive system, as evidenced by variations in the menstrual process. Hence, physiologic, 
sociologic, and psychological factors have been linked with menstrual disorders. Factors that are already known to affect menstruation are for the most part completely unrelated to occupational settings include age, body weight extremes, liver disease, thyroid dysfunction, intrauterine contraceptive devices, stress, and exercise. It is, therefore, obvious that a number of factors can affect menstruation and that these factors do not even include such things as therapeutic drugs, socalled recreational drugs, or potentially toxic substances present in occupational environments.

\subsection{Extrapolation of animal data to humans and epidemiologic studies}

It is considerably easier to extrapolate controlled drug studies in animals to exact therapeutic regimens in humans than it is to simulate a chemical's exposure in an animal to a presumed environmental exposure in humans.

Epidemiology is increasingly important in establishing cause-and-effect relationships. Epidemiology and risk assessment are inextricably related. There is a need for more well designed studies in order to implicate any individual chemical because in most occupations, workers are exposed to raw, intermediate and finished products and there are also confounding factors associated with lifestyles responsible for reproductive dysfunction. Occupational exposure are always higher than environmental exposures, so that epidemiological studies should be conducted on chemicals which are reported to have adverse effects on reproduction in the experimental system [13]. By closely monitoring worker exposures to industrial/environmental toxicants, safer conditions will be established.

\section{Preventative and protective measures}

Health and safety are essential elements of the quality of work and represent one of the more important fields of the regulatory activity of the ILO and the social policy of the European Union [3]. This, evidently, should be reflected in the legal system of each of the Member States, among them Spain. In this respect it is necessary to bring up Spanish Act 31/1995, of 8 November, ruling occupational risks, the content of which has been complimented and/or modified by Act 54/2003, of 12 December. This Act reforms the regulatory framework dealing with the prevention of hazards in the workplace claiming, in accord with the statement of its motives, that the planning of preventative measures should not be a merely formal act. This action plan should, therefore, be produced at the same time as the design of a managerial project assessing the inherent hazards in a job and being updated periodically, as the circumstances and conditions of the job change, all this being presented in a coherent and integrated ensemble of preventative measures, appropriate to the nature of the hazards and effectively controlling the same, in order to reduce the accident rate in the workplace.

With the objective of obtaining the desired result, the preventative policy is reinforced by the specification in Article 16 of the APOR of a new measure. The action plan for the prevention of occupational risks is a document which ought to 
be drawn up by all employers. This will then be integrated into the general managerial system of the business, in both the complete range of activities and in all hierarchical levels. This plan should detail the organisational structure, the processes, and the resources necessary to carry out the precautionary measures required to prevent occupational risks within the business.

Risk assessment plays a fundamental role in the action plan, in accordance with that made mandatory in Article 16.2 of the APOR. This plan should programme an initial evaluation which takes into consideration, in a general manner, the nature of the duties involved, the characteristics of the existing jobs, and of the workers who perform them. The plan should be updated when the working conditions change and due to these changes injuries to workers' health have occurred. Additionally, at the end of Article 16.2.a, it specifies that "when the result of the assessment makes it necessary the employer will make periodical inspections of the working conditions and the duties of the workers in services rendered, in order to detect potentially dangerous situations."

It will therefore be obligatory to carry out an objective survey of the hazards which could combine in a determined place of work, but this is not sufficient as the result obtained should have to be made specific, in other words its efficiency should be confirmed in the moment of being applied to a specific worker [14], with the objective of complying with the general principle which claims that it is the place of work which ought to be adapted to the worker (Article 15.1 of the APOR) and not vice versa.

Working on this principle, in regard to the occupational risks which can harm the right to have children, we should mention what is established in Article 25.2 of the APOR $[15,16]$ which emphasises that when it comes to risk assessment the exceptional way in which hazards can harm this aspect of the worker should be taken into consideration. The precept, using scientific terminology, establishes that "the employer ought to take into consideration in risk assessment the factors which may influence the procreative capacity of the workers, in particular from exposure to physical, chemical and biological agents which may cause children to be born with deformities or have a toxic effect on procreation, both in the area of fertility and in the development of offspring, with the objective of introducing the necessary preventative measures".

In accordance with the aforementioned, in the first place we should emphasise that this specific protection should be applied to all workers who can have children, unless the impossibility of their so doing is reliably corroborated [15]. We make this precise distinction because the reference in Article 25 of the APOR to the "protection of workers who are particularly sensitive to certain risks," could lead to an error, as Article 25.2 demands an disinterested protection against certain risks, and not the selective protection of some groups of workers.

Secondly, we should underline that the assessment of risks which can affect procreation may encounter certain difficulties as, to-date, there have not been enough medical studies which confirm the existence of a cause-effect relationship between the execution of a job within certain working conditions and fertility problems or deformation in offspring [1]. Due to this, as established by the European Council [3], in order to implement a culture of prevention it is 
necessary to improve awareness of the risks posed by the agents involved, systematically gathering information and scientific reports, and coordinating the respective programmes with research centres, in order to direct them to the solutions of problems and to transfer the results to business. It should be highlighted that in the year 2000, a Communication from the Commission was adopted. This Communication provided guidelines for the assessment of chemical, physical and biological agents, as well as the industrial procedures considered to be dangerous to the health of a pregnant worker, one who has recently given birth or who is breast-feeding [17] which could be useful material for assessment, even if the toxic agents which affect pregnant or breast-feeding women at work are not the same as those which affect fertility.

When dealing with risk assessment it is essential to bear another important question in mind. We have clarified that protection against the harmful effects on procreation is too generic and consequently needs to be differentiated from the general potential harm which could be caused to men and women. In other words, the gender variant should be taken into account as a criterion of diversity [4], to show clearly that some risks can affect both males and females alike, while others will have a more virulent effect on only one of the sexes. Consequently, an action plan ought to take into account this relevant circumstance, as is highlighted in Article 16.1.a of the APOR which specifies that the initial risk assessment will take into consideration "the nature of work, the characteristics of the existing jobs and the workers who do them." In order to achieve this the employer could be given professional advice by the prevention services (Article 31.3.a of the APOR), and by the Health and Safety Committee (the specialist body for the representation of workers regulated by Article 39.1.a of the APOR), bodies which have the possibility of a more direct contact with the affected wage-earners allowing the workers themselves to contribute, from their own experience, anything which may have a bearing on the matter.

Thirdly, according to Article 16.2.b of the APOR, if the results of the assessment make certain hazardous situations clear, for example if after readings are taken it is concluded that the exposure to certain chemical or physical elements exceeds the exposure limit values, the employer must take such measures as are necessary to eliminate or reduce and control this exposure. In other words, if after the appropriate assessment the existence of risks which may affect the right of the workers to have children are detected, such risks must be eliminated. However, if that is not a possibility, they should reduced and monitored by means of, for example, the use of the appropriate individual equipment or the preparation of a catalogue of products and techniques which involve a risk for the worker, with an attachment detailing the necessary protective measures for the evasion or reduction of risk. To this effect, it will be necessary to analyse the alternatives to prevention which exist, in accordance with the context in which the potentially affected worker is found. Article 16.2.b of the APOR states that preventative activities will be a planning objective for the employer, including for each action "the deadline for appointing a person to be in charge and the human resources and equipment necessary for their fulfilment" which will require a prior study, such as that which we have 
discussed. The employer will then be obliged to detect inadequate measures as a consequence of planned periodical inspections, which will then be modified to meet the level of protection required.

In the worst case scenario where, even if an action plan exists and the appropriate assessment has been carried out, discovering certain risks for procreation but, despite this, the hazardous elements have not been eliminated or replaced, or the necessary preventative measures have not been introduced, the employer could be charged as liable for a serious or very serious administrative sanction, depending upon the magnitude of the risk to the worker.

\section{Conclusions}

- Industrial processes imply that an estimated 50,000 to 60,000 chemicals have come into common use. Approximately 600 or more new chemicals enter commerce each year.

- Occupational exposure figures are inexact, and environmental levels are even more difficult to document. Exposure usually involves chemical mixtures, and individuals may not be aware of all the chemicals with which they come into contact. Thus, the effect of individual chemicals is difficult to assess, and cause-and-effect relationships are nearly impossible to establish.

- The action plan, which should be drawn up by every employer, should specifically take into account when assessing the hazards involved in carrying out a particular job in a specific working environment, the factors which can have a bearing on the ability of the individual to have children, making a distinction between hazards which can affect women, and those which can affect men.

- Objective risk assessment should be made more specific, taking into consideration both the characteristics of the job and the individual by whom said job is done.

- If, after due assessment, the employer detects situations which pose a risk to the fertility of workers, measures must be introduced which eliminate, reduce or control said hazards, otherwise said employer will be incumbent to a serious, or very serious, administrative liability, according to the magnitude of damage caused.

\section{References}

[1] Pérez del Río, T. \& Ballester Pastor, M.A., Woman and Health at Work, La Ley, Madrid, p. 46, 2000.

[2] Gómez Sánchez, Y., The Right to Human Reproduction, Marcial Pons, Madrid, p. 40, 1994.

[3] Decision of 3 June 2002, On a new strategy for health and safety in the workplace (2002-2006), Official Journal of European Community, 161, 5 June 2002. 
[4] Arial Calama, I., Occupational health for women: beyond reproductive health. New situations for Labour Law: family, immigration and the concept of the worker, ed. J. López López, Marcial Pons, Madrid, p. 183, 2001 .

[5] Thomas, M.J. \& Thomas, J.A., Toxic responses of the reproductive system. Casarett \& Doull's Toxicology: The Basic Science of Poisons, ed. C.D. Klaassen, McGraw-Hill, $6^{\text {th }}$ ed., 2001.

[6] Lenz, W., Thalidomide and congenital abnormalities. Lancet, 1, p. 1219, 1962.

[7] Bakoglu, M., Karademir, A. \& Ayberk, S., An evaluation of the occupational health risks to workers in a hazardous waste incinerator. $J$ Occup Health, 46(2), pp. 156-64, 2004.

[8] Prieto, M.J., Marhuenda, D., Roel, J. \& Cardona, A., Free and total 2,5hexenedione in biological monitoring of workers exposed to n-hexane in the shoe industry. Toxicol Lett., 145(3), pp. 249-60, 2003.

[9] Correa, A., Gray, R.H., Cohen, R., Rothman, N., Shah, F., Seacat, H. \& Corn, M., Ethylene glycol ethers and risk of spontaneous abortion and subfertility. Am J Epidemiol., 143(7), pp. 707-14, 1996.

[10] Gorospe, W.C. \& Reinhard M., Toxic effects on the ovary of the nonpregnant female. Reproductive Toxicology, ed. R.J. Witorsch, $2^{\text {nd }}$ ed., New York, Raven Press, pp. 141-157, 1995.

[11] Clegg, E.D., Perreault, S.D. \& Klinefelter, G.R., Assessment of male reproductive toxicity. Principles and Methods of Toxicology, ed. A.W. Hayes, $4^{\text {th }}$ ed., Philadelphia, Taylor \& Francis, pp. 1263-1300, 2001.

[12] Turner, H.E. \& Wass, J.A.H., Gonadal function in men with chronic illness, Clin Endocrinol, 47, pp. 379-403, 1997.

[13] Kumar, S., Occupational exposure associated with reproductive dysfunction. J Occup Health, 46(1), pp. 1-19, 2004.

[14] Fernández Marcos, L., Comments on the Act for the prevention of occupational risks and regulatory guidelines, $2^{\text {nd }}$ ed., Dikynson, Madrid, 2001.

[15] Rodriguez Ramos, M.J. \& Pérez Borrego, G., Groups at Particular risk in the Act on the prevention of occupational risks. Occupational Risk Prevention, eds. A. Ojeda, M.R. Alarcón \& M.J. Rodríguez Ramos, Aranzadi, Pamplona, p. 409, 1996.

[16] García-Perrote Escartín, I., Protection of workers who are particularly sensitive to certain hazards. Health and Safety at Work, eds. M.E. Casas, M.C. Palomeque \& F.Valdés Dal Ré, La Ley, Madrid, p. 41, 1997.

[17] European Community Communication COM (2000), 466, 5 October 2000 . 